\author{
Оксана Юрьевна Чуйкова
}

Россия, Российский государственный педагогический университет им. А.И. Гериена

\title{
«Точки» и «запятые» в структуре ситуации: абсолютный и относительный предел и средства их выражения (аспектуальные характеристики и падеж прямого дополнения) ${ }^{1}$
}

Ключевые слова: русский язык, структура ситуации, широкий контекст, накопитель эффекта, абсолютный и относительный предел ситуации, градационные глаголы, делимитативный способ действия, семельфактивный способ действия.

Key words: Russian language, event structure, wide context, incremental theme, relative and absolute boundedness, degree achievements, delimitative Aktionsart, semelfactive Aktionsart.

\begin{abstract}
The paper deals with some features of the event structure that influence its formal expression and determine the wider context of a clause. The notion of relative/absolute boundedness is used to indicate the exhaustiveness of the event. The relative boundedness is a feature that makes it possible to use the genitive partitive case as the direct object. Within such perfective verbs as vypit' 'drink.PF' and sjest ' 'eat.PF', the nominal case determines the interpretation of a verbal phrase: the accusative indicates the absolute boundedness while use of the genitive results in the relative boundedness. As for degree achievements, delimitative Aktionsart and semelfactive Aktionsart, it is the verb that determines the interpretation of a verbal phrase. What all the examined cases have in common is that the use of the genitive as the direct object marker indicates the relative boundedness (partial resultativeness): the object of the event is a part of the cumulative object of a wider (actual or ideal) situation.
\end{abstract}

1 Исследование выполнено при финансовой поддержке РФФИ в рамках научного проекта № 19-312-60006 «Прямое дополнение и аспектуальные характеристики славянского глагола». 


\section{0. Введение}

В статье рассматриваются некоторые особенности структуры ситуации, влияющие на ее формальное выражение и имплицитно определяющие широкий контекст, в котором возможно употребление высказывания. Таким образом, речь пойдет о характеристиках, влияющих на способность описываемой ситуации выходить за пределы одного высказывания и, следовательно, действовать на уровне текста. В центре внимания оказывается аспектуальное противопоставление абсолютного и относительного предела ситуации (см. [Bondarko 1986: 17; 2011: 365-366]). Абсолютный предел указывает на исчерпанность ситуации, относительный же предел, наоборот, предполагает незавершенность ситуации (что имплицитно указывает на возможность ее существования и продолжения за пределами высказывания). В рамках представления о пятичастной структуре ситуации [Plungân 2000/2003: 297; 2011: 384] (см. также [Dik 1989; Smith 1991; Klein 1994] и др.), которая включает следующие фрагменты (указаны в порядке следования во времени): подготовительная стадия, начало, середина, финал и результирующая стадия, указание на абсолютный предел безусловно имеет место только в случае, когда глагольным предикатом обозначен финал ситуации.

Возможности предиката, указывающего на относительный предел ситуации (в данном случае выраженный глаголом делимитативного способа действия (далее - СД)), наглядно демонстрирует следующий отрывок:

(1) - А вы что, уже уходите? - спросил Кролик.

- А что, у вас разве ещё что-нибудь есть? - спросил Пух. - Ты никуда не торопишься Пятачок?

- Hem.

- Ну тогда мы посидим ешё немного.

И они посидели ешё немного. Потом ешё немного. А потом ещё немного. И ешё немного. Пока, увы, совсем ничего не осталось [м/ф «Винни Пух идет в гости», 1971].

Следует отметить, что употребление в контекстах, подобных (1), возможно далеко не для каждого глагола совершенного вида (далее - CВ), а лишь для таких, которые обозначают относительный предел ситуации. В качестве диагностического теста на возможность продолжения ситуации после достижения относительного предела предлагается проверка способности глагольного предиката использоваться в контексте типа ' $X$, a потом еще $X$ '.

Следует также отметить, что в случае установления между предикатом и его аргументом инкрементального (накопительного) отношения (англ. «incremental relation» [Dowty 1991]), предполагающего наличие прямой зависимости между временной протяженностью ситуации и мерой вовлеченности объекта в ситуацию, предельность ситуации определяется признаками 
не только предиката, но и прямого объекта. Для такого объекта в русской аспектологии принято название «накопителя эффекта», или «накопителя» [Padučeva 2004; Melig 2008] (также можно встретить названия «градуальный паценс» и «инкрементальная тема» [Tatevosov 2011: 479]). Именные группы, реферирующие к объекту-«накопителю», подразделяются на два основных класса: кумулятивные и квантованные (первые, в отличие от вторых, обладают свойствами аддитивности и подразделимости), см. [Krifka 1989: 75]. Вопросы взаимодействия свойств объекта-«накопителя» и аспектуальной интерпретации глагольной группы рассматриваются в рамках теории аспектуальной композиции (см., например, [Krifka 1989; Dowty 1991; Filip 1999; Tatevosov 2015] и др.). Ниже будут рассмотрены случаи, демонстрирующие накопительное отношение в сочетании глагольного предиката и объекта, однако остающиеся как правило за пределами рассмотрения в рамках теории аспектуальной композиции в русском языке.

\section{1. «Предельные» глаголы: выпить, съесть}

Применительно к материалу русского языка теория аспектуальной композиции постулирует невозможность употребления кумулятивной именной группы при глаголе СВ, в данном случае возможно употребление только квантованной именной группы - конечной и количественно определенной. Действительно, примеры (2)-(3) предполагают полное вовлечение в ситуацию количественно определенного объекта, что как следствие приводит к невозможности существования той же самой ситуации за пределами высказывания ввиду того, что ее объект оказывается исчерпан (см. также [Tatevosov 2015: 144]). В связи с этим в естественных примерах за рассматриваемой ситуацией следуют действия, указывающие на ее полное завершение (облизать ложку, поставить стакан обратно), а сочетания, предполагающие продолжение ситуации, оказываются невозможными.

(2) Тогда Борька съел кашу $u^{\text {оК } о б л и з а л ~ л о ж к у ~[А . ~ Я ш и н, ~ М а л е н ь к и е ~ р а с с к а з ы ~}$ (1954-1962)] [ (* и еще немного осталось / *а потом еще немного съел каму);

(3) Пестренький с удовольствием выпил воду ${ }{ }^{\mathrm{OK}}$ поставил стакан обратно под кран [Н. Носов, Незнайка в Солнечном городе (1958)] (*и еще немного осталось / *а потом еще немного выпил воду).

В то же время в русском языке существует средство для выражения глаголами СВ съесть и выпить ситуации, не достигшей своего естественного

2 Здесь и далее источником языкового материала, если не указано иное, служит Национальный корпус русского языка (HКРЯ, URL: http://ruscorpora.ru). 
предела. При использовании в позиции прямого дополнения имени в форме родительного (партитивного) падежа существование одной и той же ситуации (с тождественным объектом) за пределами рассматриваемого высказывания мыслится допустимым. Таким образом сочетание глагола СВ и родительного падежа дает указание на относительный предел ситуации, что делает возможным существование таких примеров, как (4) и (5):

(4) - Еще выпьешь бульону? Бульону ему не хотелось - даже маминого, крепкого и ароматного; он и одну чамку едва в себя влил [А. Берсенева, Возраст третьей любви (2005)];

(5) Давай еще съедим шоколадного и сливочного, хоромо? [К.А. Федин, Первые радости (1943-1945)].

Примеры (4) и (5) позволяют судить о том, что ситуация с тем же объектом существовала ранее, не исключено также ее продолжение в будущем.

\section{2. Градационные глаголы}

В семантике видовых пар типа дряхлеть/одряхлеть, слабеть/ослабеть не содержится указания на естественный предел, после достижения которого ситуация перестанет иметь место. Тем не менее, несмотря на отсутствие естественного, предопределенного самой логикой ситуации предела, в течение процесса возможно достижение множества промежуточных результатов. На данный тип семантических отношений в видовых парах обратила внимание М.Я. Гловинская [Glovinskaâ 1982]. К данному типу автором были отнесены «непредельные глаголы, которые в обеих видовых формах в равной мере выражают результативное действие» [Glovinskaâ 1982: 86]. Глагол несовершенного вида (далее - НCВ) обозначает непредельный процесс, глагол СВ - достижение некоторого промежуточного результата в ходе данного процесса. В настоящее время такие глаголы, вслед за Е.В. Падучевой, называют «градативами» [Padučeva 1996: 117-118], или «градационными парами» [Zaliznâk, Šmelev 2000: 57-58]. Предел в рассматриваемых парах задается количественно [Padučeva 1996: 118-119; Zaliznâk, Šmelev 2000: 57]. В работах А.В. Бондарко постулируется, что отношения между коррелятами в градационной паре следует считать предельными, только предел в данном случае является относительным (в противопоставление абсолютному пределу, наличие которого отличает бесспорные предельные пары) [Bondarko 1986: 17; 2011: 365-366].

Относительный характер предела, эксплицитно выражаемого СВ в градационных видовых парах, дает возможность существования ситуации, выраженной данным глаголом за пределами одной клаузы, см (6). 
(6) Сперва он чувствовал тяжесть ноши по обыкновенному весу человека; потом тяжесть уменьшилась, а потом и еще уменьшилась, почти сделалась нечувствительною [епископ Игнатий (Брянчанинов), Отечник (1863)].

Употребление градационных глаголов возможно в сочетаниях с объектом«накопителем». В первую очередь это глаголы, содержащие в своей семантике идею увеличения/уменьшения количества или степени проявления признака, например, прибавить, убавить (см. пример (7)). Кроме того, сюда также относятся относительно многочисленные группы глаголов, относящихся к определенным способам глагольного действия: комплетивно-партитивному с префиксами под-, над-, до- и при- (см. примеры (8)-(9)), отделительно-партитивному с префиксом от- (см. пример (10)), кумулятивному с префиксом на- (см. пример (11)).

(7) Но вместо того, чтобы устремиться туда, Иван еще убавил газ и валко съехал на боковую дорогу, в поднявшуюся облаком белесую взвесь [О. Славникова, Стрекоза, увеличенная до размеров собаки (1995-1999)];

(8) Страхов часто-часто заморгал фарами, выражая свою признательность парням, а «Нива» еще прибавила скорость и исчезла, удачно проскочив на зеленый свет [Л. Корнешов, Газета (2000)];

(9) После Нового года установилась настоящая зима. Подморозило, еще подсыпало снега [Н.Ф. Королева, Другая собака, «Наука и жизнь», 2007];

(10) Петруха еще отпил водки, закусил тем же калачом и сунулся к окну, поглядел на реку [А.П. Чапыгин, На лебяжьих озерах (1923)];

(11) - Ничего... - Хлеба еще нарезать? - Хватит [С. Таранов, Черт за спиной (2001)].

Интересно, что при градационных глаголах регулярно наблюдается возможность оформления прямого дополнения формой родительного падежа с партитивной семантикой. В отличие от рассмотренных выше случаев употребления глаголов съесть и выпить, где падежная форма дополнения определяет интерпретацию глагольной группы, в случае с градационными глаголами интерпретация задается глагольной лексемой, а падежные формы родительного и винительного падежей семантически не противопоставлены и могут употребляться как синонимичные друг другу (однако в ряде случаев форма родительного падежа оказывается предпочтительной).

\section{3. Делимитативные глаголы}

Глаголы делимитативного СД с префиксом по- «описывают некоторую „порцию” действия, оцениваемую как небольшую и ограниченную временем, в течение 
которого оно производилось» [Zaliznâk, Šmelev 2000: 111]. В приведенном выше примере (1) глагол посидеть относится к делимитативному СД.

В литературе бытует точка зрения на русский делимитатив как на своеобразный способ «компенсации», расширения системы видового противопоставления на непредельные глаголы [Dickey 2006]. С.Г. Татевосов предлагает считать глаголы делимитативного (и пердуративного) СД своеобразным исключением, демонстрирующим сочетаемостные особенности глагола HCB [Tatevosov 2011]. Делимитатив трактуется как глагол СВ, при котором возможно употребление кумулятивного (недискретного, количественно неопределенного) имени. В литературе также отмечается сходство глаголов делимитативного СД и градативов: «нетривиальное соотношение в паре повыситься/повышаться может быть представлено как аналогичное соотношению глагола ограничительного способа действия с мотивирующим его непроизводным, ср. сnать - поспать, гулять - погулять [...]. В обоих случаях предел задается количественно» [Padučeva 1996: 118-119]; «[к] градационным видовым парам близки пары глаголов типа гулять - погулять [...]» [Zaliznâk, Šmelev 2000: 58].

Для глаголов делимитативного СД, сочетающихся с объектом, представляющим собой накопитель эффекта, характерны те же признаки, что и для непредельных делимитативных предикатов (как в примере (1)).

(12) Вороны попили жсивой водицы, закидывая клювы вверх, приосели на хвосты, подумали и еще попили [В. Астафьев, Последний поклон (1968-1991)].

Как и при градационных глаголах, при глаголах делимитативного СД возможно употребление формы родительного падежа, которая семантически не противопоставлена форме винительного падежа (см. примеры (13)-(14)). Данное свойство отличает рассматриваемую группу как от «предельных» глаголов СВ, где использование разных падежных форм указывает на полноту вовлечения объекта в ситуацию и, соответственно, на характер предела ситуации (абсолютный или относительный), так и от глаголов НCB, не допускающих употребление родительного падежа в позиции прямого дополнения при референции к единичной ситуации в актуально-длительном значении [Wierzbicka 1967; Padučeva 1998].

(13) Мы похлебали щи, выпили, самогон забористый [Ф. Светов, Чижик-пыжик, «Знамя», 2001];

(14) Вскоре, действительно, появился дядя Гриша, громко похлебал в одиночестве борща на кухне - он ел суп утром и вечером, - спросил, где мать и сделала ли я уроки [И. Катерли, Дневник сломанной кукльы, «Звезда», 2001].

Следует отметить, что способность делимитативных глаголов к сочетанию с родительным падежом весьма непоследовательно отражена в словарях. Так, 
например, в «Малом академическом словаре» [Evgen'eva 1981-1984] вариативное управление зафиксировано у ограниченного круга глагольных лексем, в число которых в основном входят ингестивные глаголы (обозначающие ситуации поглощения еды, напитков, веществ): поглодать, поглотать, noесть, пожевать 'поесть немного', поклевать, полакать, полопать, попить, похватать 'торопливо, наспех поесть', похлебать, пощелкать и т.д. При этом анализ употреблений на материале НКРЯ и русскоязычного сегмента сети Интернет показывает, что с родительным падежом способен сочетаться практически любой глагол делимитативного СД, при условии, что объект выражается кумулятивным именем (существительные с вещественной семантикой и существительные в форме множественного числа) и вовлекается в ситуацию последовательно, как, например, в (15)-(18).

(15) Если они серьезно занимают вас - вам надо почитать книг... [М. Горький, Фома Гордеев (1899)];

(16) Я подумал, что лучшего варианта, чем пойти в библиотеку и полистать газет-жнурналов не найти [https://books.google.ru/books?id=PplGDwAAQ BAJ\&printsec];

(17) Ведь мало кому приходило в голову стать мясником, а в свободное время для души, повьводить формул в тетрадку [https://www.maybe.ru/dom/lib/2114/ forum_2014-07-01.html];

(18) Немного побаловались побросав камней в местный замерзиий фонтанчик. Пофоткали разных промышленных пейзажей со смотровой площзадки. Еще пофоткали [https://rifat.livejournal.com/217373.html].

Таким образом, можно говорить о том, что сочетаемость с родительным падежом является характерной особенностью глаголов делимитативного СД и служит отражением заложенной в семантике данной группы глаголов идеи относительного предела ситуации.

\section{4. Семельфактивные глаголы}

Как представляется, в свете рассматриваемых явлений интересно обратить внимание также на группу глаголов семельфактивного СД, формальным показателем которого является суффикс -(a)ну-. Согласно определению [Zaliznâk, Šmelev 2000: 118], к семельфактивному СД «относят глаголы, обозначающие один „квант” деятельности, описываемой исходным глаголом» (исходный глагол в данном случае - непроизводный НСВ, обозначающий мультипликативный процесс). Строго говоря, семельфактивные глаголы не выражают относительного предела, однако представляется любопытным их сходство с делимитативами, заключающееся в том, что в обоих случаях 
способ действия выделяет некоторую часть более широкой (идеальной), разворачивающейся на более длительном отрезке времени ситуации, обозначенной глаголом НСВ. Различие между данными СД состоит в том, что делимитатив обозначает ситуацию, которая занимает некоторый (обычно непродолжительный) временной отрезок, а семельфактив концептуализует ситуацию как мгновенную. Обозначенные данными глаголами ситуации различаются также с точки зрения степени произвольности их вычленения из широкой денотативной ситуации. По мнению Х.Р. Мелига, глагол одноактного (= семельфактивного) способа действия представляет собой «глагольный сингулятив», который образуется «только тогда, когда обозначаемая ситуация предполагает внутреннюю расчлененность на ряд последовательных однородных актов» [Melig 1994: 598]. В отличие от семельфактива, у делимитативного СД «временной [...] объем выделенного кванта остается открытым» [Melig 1994: 593], это означает, что фактическая длительность обозначаемой делимитативом ситуации может варьировать в широких пределах.

При условии единства и однородности объекта, вовлеченного в мультипликативный процесс, внутренняя расчлененность ситуации не препятствует употреблению семельфактивного глагола для обозначения ситуации, которая уже существовала (и/или еще может существовать после) с тем же набором участников за пределами одной клаузы (см., например, (19)-(20)).

(19) Еще хлебнув неразбавленного виски, я почувствовал себя ушедшим из семьи [Н. Климонтович, Последняя газета (1997-1999)];

(20) Колька закрыл глаза, глотнул, еще глотнул, и у него сразу все потянуло обратно [А. Приставкин, Ночевала тучка золотая (1981)].

Отмеченные различия между делимитативными и семельфактивными глаголами имеют место в «центральных случаях» реализации глагольных единиц данных типов. Реальная картина оказывается сложнее: глаголы делимитативного и семельфактивного СД демонстрируют гораздо бо́льшую близость, чем было обозначено выше. Так, некоторое количество глаголов с суффиксом -(a)ну- имеет значение, которое может быть определено как ограничительное, ср. жевануть $\approx$ пожевать (21), курнуть $\approx$ покурить (22).

(21) У Крымова глаза увлажнились, так сильно ему вдруг захотелось жевануть пирожкка с капустой [В. Гроссман, Жизнь и судьба, часть 3 (1960)];

(22) Несколько раз нам с любезно-криминальной ульбочкой предлагали курнуть гашиша [Д. Рубина, Воскресная месса в Толедо (2000)].

Употребление формы родительного падежа в позиции прямого дополнения также характерно для глаголов семельфактивного СД. Как и в случае с градационными и делимитативными глаголами, формы родительного 
и винительного падежа могут использоваться без видимого семантического противопоставления, ср. примеры (23)-(24).

(23) А что до иеремоний, - по-русски не вынимая ложку из стакана, Сергей глотнул чай, - то этого не люблю [П. Крусанов, Перекуем орала на свистела (2001), «Нева», 2004];

(24) Она же теперь по всей вашей истории разоблачается... - Взглянул внимательно, снова глотнул чаю. - Так вот, турки еще дважды за несколько лет нападали [А. Пашкевич, Сим победиши, «Сибирские огни», 2013].

Анализ употреблений ряда глаголов (таких как глотнуть, дернуть, долбануть, жевануть, капнуть, клюнуть, куснуть, курнуть, лизнуть, махнуть, махануть, нюхнуть, плескануть, плеснуть, сыпануть, хватануть, хлебнуть, хлобыстнуть, хлопнуть, хряпнуть, черпануть) показывает, что несмотря на возможную конкуренцию форм винительного и родительного падежа, использование последнего при семельфактивных глаголах оказывается количественно преобладающим и более предпочтительным.

\section{5. Выводы}

Приведенный выше анализ позволяет сделать вывод, что глагол СВ в русском языке не всегда указывает на завершенность ситуации и невозможность ее продолжения. Целый ряд русских перфективных глаголов в своей семантике содержат указание на возможность существования ситуации за пределами одной клаузы, при этом данная идея может выражаться как имплицитно, так и при помощи формальных средств (сочетание с еще, еще немного). Диагностическим критерием для определения характера предела ситуации, и соответственно, ее способности функционировать в более широком контексте, может служить также сочетаемость глагола с формой родительного падежа прямого объекта (при условии, что объект является накопителем). Форма родительного падежа прямого дополнения указывает на относительный предел / неполную результативность - объект, вовлеченный в ситуацию, представляет собой часть совокупного объекта, вовлеченного в более широкую ситуацию (реальную или идеальную). При этом падежная форма может как обусловливать интерпретацию глагольной группы (как в случае с глаголами съесть и выпить), так и просто коррелировать с семантикой глагольной лексемы. Последнее наблюдается при употреблении градационных глаголов, глаголов делимитативного и семельфактивного СД: данные глаголы способны сочетаться с формами родительного и винительного падежа прямого дополнения, при этом в случае замены падежной формы не 
происходит значительного сдвига в семантике высказывания - можно говорить о синонимии родительного и винительного падежей.

\section{Литература}

Bondarko A.V., 1986, Semantika predela, Voprosy âzykoznaniâ, 1, pp. 14-26.

Bondarko A.V., 2011, Kategorizaciâ v sisteme grammatiki, Moskva: Âzyki slavânskih kul'tur. Dickey S.M., 2006, Aspectual pairs, goal orientation and PO-delimitatives in Russian, Glossos, iss. 7, http://www.seelrc.org/glossos/issues/7/dickey.pdf; 1.07.2021.

Dik S.C., 1989, The Theory of Functional Grammar. Part I: The Structure of the Clause, Dordrecht: Foris.

Dowty D., 1991, Thematic proto-roles and argument selection, Language, vol. 67 (3), pp. 547-619.

Evgen'eva A.I. (ed.), 1981-1984, Slovar' russkogo âzyka v 4-h tt., $2^{\text {nd }}$ ed., Moskva: AN SSSR, Institut russkogo âzyka, http://feb-web.ru/feb/mas/mas-abc/default.asp; 1.07.2021.

Filip H., 1999, Aspect, Eventuality Types and Nominal Reference, New York: Routledge, Taylor and Francis Group.

Glovinskaâ M.Â., 1982, Semantičeskie tipy vidovyh protivopostavlenij russkogo glagola, Moskva: Nauka.

Klein W., 1994, Time in Language, London-New York: Routledge.

Krifka M., 1989, Nominal reference, temporal constitution and quantification in event semantics [in:] R. Bartsch et al. (eds.), Semantics and Contextual Expressions, Dordrecht: Foris, pp. 75-115.

Melig H.R., 1994, Gomogennost' i geterogennost' v prostranstve i vremeni (O kategorii glagol'nogo vida v russkom âzyke), Rev. Etud. Slaves, Paris, LXVI/3, pp. 585-606.

Melig H.R., 2008, Vzaimodejstvie meždu vidom i «nakopitelâmi» v russkom âzyke [in:] Dinamičeskie modeli: Slovo. Predloženie. Tekst: Sb. st. v čest'E.V. Padučevoj, Moskva: Âzyki slavânskih kul'tur, pp. 562-593.

Padučeva E.V., 1996, Semantičeskie issledovaniâ: Semantika vremeni i vida v russkom âzyke. Semantika narrativa, Moskva: Âzyki russkoj kul’tury.

Padučeva E., 1998, On Non-compatibility of Partitive and Imperfective in Russian, Theoretical Linguistics, 24 (1), pp. 73-82.

Padučeva E.V., 2004, «Nakopitel' èffekta» i russkaâ aspektologiâ, Voprosy âzykoznaniâ, 5, pp. 46-57.

Plungân V.A., 2000/2003, Obŝâ̂ morfologiâ: Vvedenie v problematiku, Moskva: Editorial URSS.

Plungân V.A., 2011, Vvedenie v grammatičeskuû semantiku: grammatičeskie značeniâ i grammatičeskie sistemy âzykov mira, Moskva: RGGU.

Smith C.S., 1991, The parameter of aspect, Studies in Linguistics and Philosophy, 43, Dordrecht: Kluwer.

Tatevosov S.G., 2011, Interpretaciâ imennyh aktantov i modal'nyj analiz perfektivnosti, Acta Linguistica Petropolitana. Trudy Instituta lingvističeskih issledovanij RAN, vol. VII (3), Sankt-Peterburg: Nauka, pp. 478-486.

Tatevosov S.G., 2015, Akcional'nost'v leksike i grammatike. Glagol i struktura sobytiâ, Moskva: Âzyki slavânskoj kul’tury. 
Wierzbicka A., 1967, On the semantics of the verbal aspect in Polish [in:] To Honor Roman Jakobson, The Hague-Paris: Mouton, pp. 2231-2249.

Zaliznâk A.A., Šmelev A.D., 2000, Vvedenie v russkuû aspektologîu, Moskva: Âzyki russkoj kul'tury. 